\title{
How social background affects educational attainment over time in the Netherlands
}

Citation for published version (APA):

Büchner, C. I. R., \& van der Velden, R. K. W. (2013). How social background affects educational attainment over time in the Netherlands. In J. Jonson, \& M. Jackson (Eds.), Determined to succeed? Performance versus choice in educational attainment (pp. 89-115). Stanford University Press. https://doi.org/10.11126/stanford/9780804783026.003.0004

Document status and date:

Published: 01/01/2013

DOI:

10.11126/stanford/9780804783026.003.0004

Document Version:

Publisher's PDF, also known as Version of record

\section{Please check the document version of this publication:}

- A submitted manuscript is the version of the article upon submission and before peer-review. There can be important differences between the submitted version and the official published version of record.

People interested in the research are advised to contact the author for the final version of the publication, or visit the DOI to the publisher's website.

- The final author version and the galley proof are versions of the publication after peer review.

- The final published version features the final layout of the paper including the volume, issue and page numbers.

Link to publication

\footnotetext{
General rights rights.

- You may freely distribute the URL identifying the publication in the public portal. please follow below link for the End User Agreement:

www.umlib.nl/taverne-license

Take down policy

If you believe that this document breaches copyright please contact us at:

repository@maastrichtuniversity.nl

providing details and we will investigate your claim.
}

Copyright and moral rights for the publications made accessible in the public portal are retained by the authors and/or other copyright owners and it is a condition of accessing publications that users recognise and abide by the legal requirements associated with these

- Users may download and print one copy of any publication from the public portal for the purpose of private study or research.

- You may not further distribute the material or use it for any profit-making activity or commercial gain

If the publication is distributed under the terms of Article $25 \mathrm{fa}$ of the Dutch Copyright Act, indicated by the "Taverne" license above, 
C H A P T E R F O U R

\title{
How Social Background Affects Educational Attainment over Time in the Netherlands
}

\author{
Charlotte Büchner and Rolf van der Velden
}

There has been much research in the Netherlands on inequality of educational opportunity (IEO) for pupils of different socioeconomic backgrounds. Beginning with the seminal work of Van Heek (1968), the focus of this research has mostly been on the transition that pupils face at age 12 , the transition from primary to secondary education, with an overall conclusion that IEO in the Netherlands has decreased only slightly in recent decades (e.g., Bakker, Dronkers, and Schijf 1982, 1986; Bakker and Cremers 1994; Bakker and Schouten 1991; De Graaf and Ganzeboom 1993; De Jong, Dronkers, and Saris 1982; Dronkers 1983, 1993; Kloosterman et al. 2009; Peschar, Ten Vergert, and Popping 1986; Sieben, Huinink, and De Graaf 2001; Tieben, De Graaf, and De Graaf 2010; Vrooman and Dronkers 1986; Willemse 1987). However, over a longer period, the Netherlands underwent a "process of opening-up and equalization" (Blossfeld and Shavit 1993, 18). A recent study by Buis (2010) replicates the study of De Graaf and Ganzeboom (1993) but with improved data and modeling techniques. He shows that the trend toward decreasing IEO was most notable in the middle decades of the 20th century: for men, in the 1940s and 1950s, and for women, in the 1950s and 1960s. For more recent decades he found no significant trend. He also showed that at the beginning of the 20th century total IEO was mainly driven by inequalities in the transition from primary to secondary education, while toward the end of the century inequalities in the transition to postsecondary education become more relevant.

One problem with the above-mentioned studies that deal with longterm trends is that they lack data on children's academic performance. Few 
studies even ask whether changes in the distribution of academic performance across social groups or changes in the propensity to make particular educational choices across social groups might have influenced IEO. In other words, it is not possible to identify whether the observed changes in IEO were due to changes in the magnitude of primary or of secondary effects, and we do not at present have a good understanding of whether these underlying processes that drive IEO are stable or changing over time.

The studies that include data about school performance have used different modeling techniques. To our knowledge, only one study in the Dutch context assesses the relative importance of primary and secondary effects when analyzing IEO. Kloosterman et al. (2009) apply the methodological approach introduced by Erikson et al. (2005) and Jackson et al. (2007) to examine the educational transition faced by Dutch pupils at age 12 (the transition from primary to secondary education), analyzing changes in primary and secondary effects over five birth cohorts. Using performance scores and parents' education to measure primary and secondary effects, they find that the secondary effects of social background have been more or less stable, while the primary effects have fluctuated (or somewhat increased) over the cohorts. Regarding the development of IEO, the results suggest that inequalities in the transition from primary to secondary education remained more or less stable over time.

Those studies that have analyzed the relationship between social background and the transition to higher education in the Netherlands have found a positive correlation between higher social background and the propensity to make the transition to higher education (e.g., Bosma and Cremers 1996; De Graaf and Ganzeboom 1993; De Graaf and Wolbers 2003; Rijken, Maas, and Ganzeboom 2007; Tieben and Wolbers 2010). However, none of these studies considered possible changes in the relative importance of primary and secondary effects at this transition. ${ }^{1}$

In this chapter we look at the development of primary and secondary effects over time by analyzing the transitions at age 12 and at age 17 or 18 , the transition to higher education, using the models described in Chapter 2 of this book. The next section provides an overview of the Dutch educational system and the distribution of students in educational tracks over time. We then introduce the data and the model specification before presenting our findings. Finally, we summarize our findings and draw conclusions. 
The school system in the Netherlands is highly stratified from secondary education onward and can generally be divided into vocationally oriented tracks and academic tracks. The first transition, from primary education to secondary education, takes place at age 12 . The transition to higher education (vocational colleges and universities) takes place at age 17 or 18 , depending on which secondary education track the student followed (see Figure 4.1). The structure of the secondary education system in the Netherlands was largely shaped by the Mammoth Law of 1968, which moved the country toward an integrated system. Before this law came into effect, secondary education consisted of four educational tracks organized in different institutions. Pupils were admitted to one of these tracks at age 12 on the basis of entry examinations, and they had little or no possibility of moving to a higher track. The Mammoth Law maintained the different hierarchical school types of the old system but facilitated transitions to secondary education through orientation classes (brugklas) in the first and

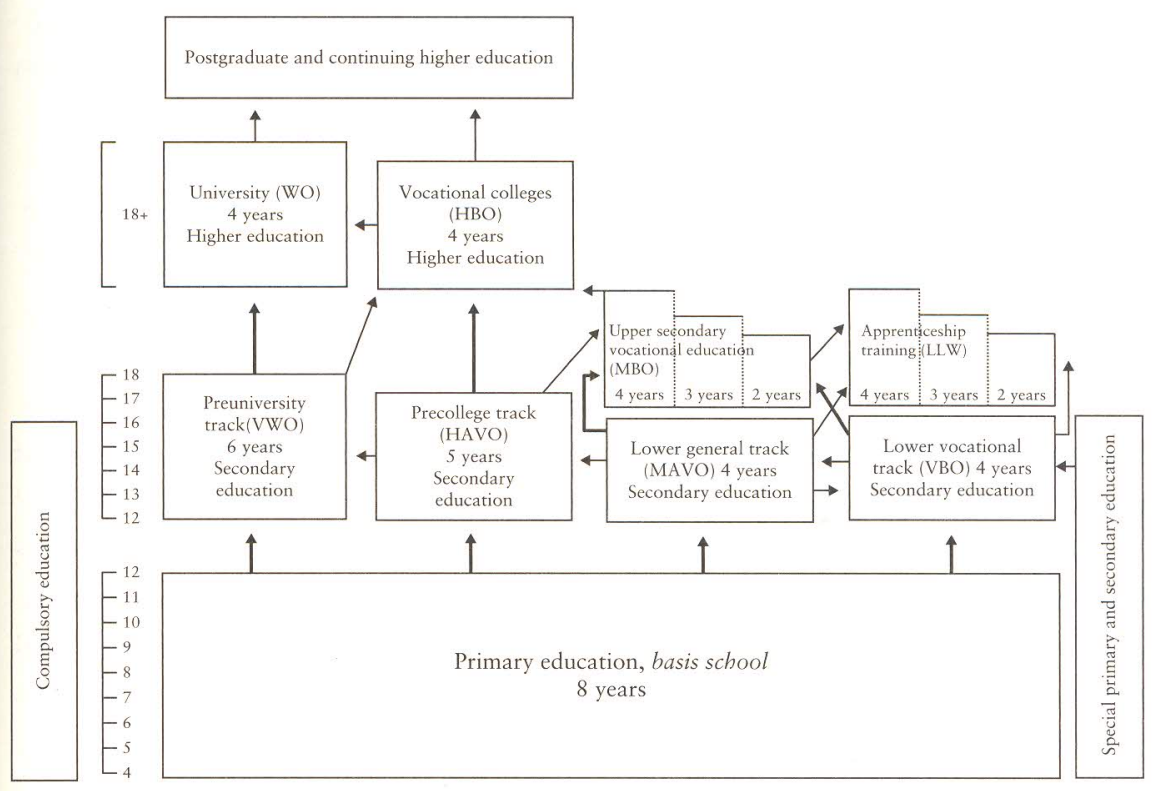

Figure 4.1. The Dutch educational system 
sometimes second grade of secondary education. These orientation classes were meant to postpone track placement until the end of the first or second grade. In many cases the orientation classes combined two adjacent tracks, but schools were autonomous in the way that they implemented this: some maintained separate classes for each track, and others combined all four tracks of secondary education. The Mammoth Law also stimulated the formation of school communities in which different tracks of secondary education were combined within one building, which made it possible for more students to change tracks without changing schools. Furthermore, at the end of primary school, nationwide standardized skills tests (the socalled $\mathrm{CITO}^{2}$ tests) and class teacher recommendations were introduced to structure the selection into different tracks in secondary education (see Dronkers 1993, 262-63). The CITO tests are used to measure school performance in the final grade of primary education in language, mathematics, and information processing. Although the CITO tests are not mandatory, most primary schools (about 92 percent) use them to assess their pupils (CITO 2010).

As shown in Figure 4.1, compulsory education starts with primary education at age 4 and ends at age $16 .{ }^{3}$ Primary education, organized in the socalled basisschool, lasts for eight years, until age 12 . Secondary education is distinguished in four tracks, three general and one vocational:

- preuniversity education (VWO): the preuniversity track

- higher general secondary education (HAVO): the precollege track

- intermediate general secondary education (MAVO): the lower general track

- prevocational education (VBO): the lower vocational track

Both primary education and secondary education also have a system of special education for pupils with learning problems or physical disabilities. ${ }^{4}$

The arrows in Figure 4.1 indicate the possible routes for proceeding from one track to another in the educational system, with bold arrows indicating the main routes. Vertical upward transitions to the higher school tracks are allowed when appropriate levels beneath them have been completed. Downward transitions to lower tracks are possible at any time. Only the two highest tracks in secondary education prepare students for higher education: the precollege track (HAVO) prepares for vocational colleges $(\mathrm{HBO})$ and the preuniversity track (VWO) prepares for university 
(WO). Both the lower general track (MAVO) and the lower vocational track (VBO) mainly prepare for upper secondary vocational education (MBO). In general, the lower general track (MAVO) aims to prepare students for the long (three- or four-year) tracks in upper secondary vocational education (MBO), while the lower vocational track (VBO) aims to prepare them for the short (one- or two-year) tracks and apprenticeship training. Each track after primary education follows a specified path to the next track. The system thereby also allows transitions within the secondary and postsecondary levels. The most relevant within-level transitions at the secondary level are from the lower general track (MAVO) to the precollege track (HAVO) and from the precollege track (HAVO) to the preuniversity track (VWO). At the postsecondary level, the most relevant transitions are from upper secondary vocational education $(\mathrm{MBO})$ to vocational colleges $(\mathrm{HBO})$ and from vocational colleges ( $\mathrm{HBO}$ ) to university (WO).

In 2000 the Dutch Ministry of Education, Culture, and Science introduced the concept of a starting qualification (startkwalifikatie) to establish a minimum credential for young people that confers eligibility for the labor market. Those who do not attain a starting qualification are considered to be early school leavers. Diplomas from the precollege track (HAVO), preuniversity track (VWO), and upper secondary vocational education of at least two years (MBO at level two, which is the level of a basic skilled worker [Traag and Van der Velden 2011]) all provide a starting qualification. Although compulsory education ends in the year that pupils turn 16 (leerplicht), they are obliged to stay in school until obtaining the starting qualification or turning 18 (kwalificatieplicht).

The two transition processes under study, the transition at age 12 from primary to secondary education and the transition at age 17 or 18 from secondary to higher education, are quite different in terms of the underlying process. At the transition at age 12, pupils are selected mainly on the basis of their performance on the CITO test and their schoolteacher's recommendation. Although this seems to leave little room for nonmeritocratic factors, the secondary effects of social stratification do play a role. First, the teacher's advice is not only based on a pupil's past performance but also on motivational aspects and expected success in secondary education. The children of higher social classes are expected to be more successful and are consequently steered toward higher courses (Dronkers 1993). Second, much of the advice is mixed (e.g., MAVO and HAVO, or HAVO and VWO), ${ }^{5}$ 
which leaves room for the parents to negotiate placement in the higher of the two tracks, an option that parents from higher social classes are usually keen to embrace. Finally, the management of secondary schools has autonomy when it comes to decisions about whether to admit pupils and can therefore diverge from test results or advice. This again opens up room for negotiation by the parents.

The transition to higher education at age 17 or 18 depends very much on attainment at the secondary education level. Having gained a diploma from the preuniversity track (VWO), the student gains automatic access to university (WO), while a diploma from a precollege track (HAVO) gives automatic access to vocational college ( $\mathrm{HBO}$ ). Both types of diplomas are awarded on the basis of nationwide and schoolwide examinations. The examinations ensure that the quality of diplomas is more or less similar nationwide. Some programs in higher education, however, may impose additional requirements on students (for example, access to higher-education programs in medicine and the arts is restricted). Although a preuniversity track (VWO) diploma grants access to university (WO) and a precollege track (HAVO) diploma to vocational college (HBO), not every student will choose to take that path. Some preuniversity track (VWO) students choose the less prestigious vocational college $(\mathrm{HBO})$ programs and some precollege track (HAVO) students choose an upper secondary vocational education $(\mathrm{MBO})$ program that is not considered part of higher education. Alternatively, these students may decide not to study at all. As there are no entrance criteria other than having the required diploma from secondary education, we expect that the transition at age 17 or 18 to higher education is driven by secondary effects rather than by primary effects of social stratification.

In the web appendix (http://www.primaryandsecondaryeffects.com) we provide additional information on the development in enrollment for the different types of education over time (see Figures A4.1 and A4.2).

\section{DATA AND MODEL SPECIFICATION}

Our analysis is based on panel datasets of four education cohorts provided by Statistics Netherlands (Centraal Bureau voor de Statistiek; CBS 1992). Each dataset is a nationally representative sample, and pupils are observed, starting at age 12 when they enter secondary education, in 1977 ( $N=$ 37,280), $1982(N=16,813), 1989(N=19,524)$, and $1993(N=20,331)$. The 
pupils in each cohort are followed until the end of their full-time education or until age 28 . We refer to the cohorts by the year the pupils were born, that is, 1965, 1970, 1977, and 1981. Each dataset provides comparable information on the socioeconomic background and standardized skills tests of pupils at the entry to secondary education. School track choices and whether a final examination was passed are documented by the schools participating in the four surveys and are provided each year for all students. ${ }^{6}$

Unlike for other countries in this book, our measure of social background is based solely on the highest educational level achieved by the parents. The occupational information in the data does not allow differentiation into social classes as conventionally defined. However, as demonstrated by several Dutch studies (e.g., Bakker and Cremers 1994; De Graaf and Ganzeboom 1993), the impact of father's occupational status on children's educational attainment appears to have decreased over time, while father's educational level is a much stronger and more stable predictor of children's educational attainment. This finding supports the assumption that the Netherlands, compared to other European countries (e.g., England), is a "knowledge-based" society rather than a "class" society (Kraaykamp, Van Eijck, and Ultee 2010). The lack of social-class measures in our data, however, means that we cannot compare the role of social class and parents' education in educational inequality, nor can we consider the role of social class in determining the relative importance of primary and secondary effects.

\section{Dependent Variables}

As discussed above, we aim to investigate the relative importance of primary and secondary effects over time at two stages of the educational career: the transition to secondary education, when pupils are 12 years old, and the transition to higher education, when pupils are aged 17 or 18. Figure 4.2 illustrates the transitions in the Dutch school system for the 1981 cohort and shows the transition and completion rates for the secondary and postsecondary levels. The proportions of students making the transitions to the different tracks in secondary education have hardly changed over time. ${ }^{7}$ Around 30 percent of all pupils of each cohort go to one of the higher tracks (the precollege track HAVO or the preuniversity track VWO). The vast majority of them also complete their chosen track. The share of pupils completing a precollege track is even higher than the share of pupils 


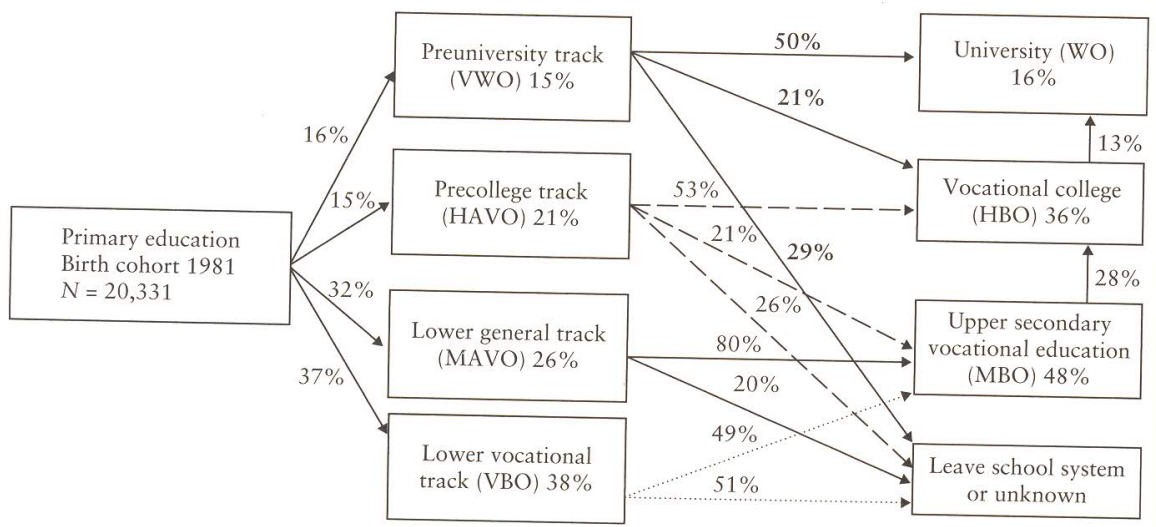

Figure 4.2. Transition and completion rates in secondary and postsecondary education, 1981 birth cohort

SOURCE: 1981 CBS cohort; our calculations.

NOTE: The arrows represent the transition from one track to another track and add up to $100 \%$. The figures in the boxes represent the highest completed level of secondary or postsecondary education. These can differ from the inflow as a result of upward or downward mobility. For the transition at age 12 we have information for all students. For the transition at age 17-18 we lack information for students who dropped out of the panel or who left school altogether; they are in the category "Leave school system or unknown."

entering the track, because of upward movements of pupils from the lower general track (MAVO) (for completion rates see percentages in Figure 4.2).

Clearer changes over time occur at the transition to postsecondary education (see Table 4.1). The share of pupils from the preuniversity track (VWO) entering university (WO) increased from 45 percent in the 1965 cohort to 50 percent in the 1981 cohort. The largest increase occurred with the transition to vocational colleges (HBO). The rates of transition from the precollege track (HAVO) to vocational college continuously increased from 31 percent (1965 cohort, see web appendix Figure A4.3) to 53 percent (1981 cohort, see Figure 4.2). The growing popularity of vocational college is also evident from completion rates and transfers to this track. In the 1965 cohort 26 percent of all pupils obtained a vocational college certificate. Included in this group are 11 percent of those who entered upper secondary vocational education ( $\mathrm{MBO}$ ), later transferring to vocational college. By the 1981 cohort the number of vocational college graduates had increased to 
TA B LE 4 . I

Descriptive statistics (\%)

\begin{tabular}{|c|c|c|c|c|}
\hline & 1965 & 1970 & 1977 & 1981 \\
\hline \multicolumn{5}{|l|}{ Parents' education } \\
\hline Low & 53 & 51 & 44 & 30 \\
\hline Medium & 31 & 29 & 36 & 45 \\
\hline High & 16 & 20 & 20 & 25 \\
\hline \multicolumn{5}{|l|}{ Transition at age 12 to precollege } \\
\hline track (VWO) & 29 & 31 & 28 & 31 \\
\hline $\begin{array}{l}\text { Transition at age } 12 \text { to preuniversity } \\
\text { track (VWO) }\end{array}$ & 17 & 17 & 15 & 16 \\
\hline $\begin{array}{l}\text { Transition at age 17-18 from precol- } \\
\text { lege track (HAVO) or preuniver- } \\
\text { sity track (VWO) to vocational } \\
\text { college (HBO)/university (WO) }\end{array}$ & 49 & 57 & 60 & 60 \\
\hline $\begin{array}{l}\text { Transition at } 17-18 \text { from preuni- } \\
\text { versity track (VWO) to university } \\
\text { (WO) }\end{array}$ & 45 & 54 & 48 & 50 \\
\hline $\begin{array}{l}\text { Unconditional transition of all to } \\
\text { vocational college (HBO) or uni- } \\
\text { versity (WO) }\end{array}$ & 20 & 21 & 20 & 22 \\
\hline $\begin{array}{l}\text { Unconditional transition of all to } \\
\text { university (WO) }\end{array}$ & 8 & 10 & 7 & 8 \\
\hline$N$ at age 12 & 37,050 & 7,864 & 19,287 & 19,994 \\
\hline$N$ at age $17-18$ & 18,123 & 4,242 & 12,193 & 11,965 \\
\hline
\end{tabular}

S O U R C E : CBS cohorts 1965, 1970, 1977, and 1981 and our calculations.

36 percent and transfers from upper secondary vocational education $(\mathrm{MBO})$ to the vocational college certificate continuously increased over time to reach 28 percent (see Figure 4.2 and web appendix Figures A4.3, A4.4, and A4.5).

In constructing our measure of the transition at age 12 , we consider two definitions that could be considered appropriate in the Dutch case. First, we look at only pupils entering the preuniversity track (VWO), and then-in line with Kloosterman et al. (2009) — we consider pupils entering precollege track (HAVO) or preuniversity track (VWO). We think that this is a crucial distinction in the Dutch school track system, since the preuniversity track is typically considered to be an elite track, while the precollege track is usually regarded as a track for talented students from the intermediate and lower social classes. Combining these two tracks is likely to lead to an underestimation of IEO. The same type of distinction applies at the transition to higher education: the vocational track in higher education (HBO) has 
absorbed much of the increase in enrollment rates, so that vocational college typically has the status of mass education, while the university (WO) maintained its status of elite education.

Summing up, in the analyses we use the following model specifications: ${ }^{8}$

1. The probability of entering either precollege track (HAVO) or preuniversity track (VWO)

2. The probability of entering preuniversity track (VWO)

3. The conditional probability of making the transition to vocational college $(\mathrm{HBO})$ or university $(\mathrm{WO})$ given a diploma from a precollege track (HAVO) or a preuniversity track (VWO)

4. The conditional probability of making the transition to university (WO) given a diploma from a preuniversity track (VWO)

5. The unconditional probability of all students making the transition to vocational college (HBO) or university (WO)

6. The unconditional probability of all students making the transition to university (WO)

\section{Independent Variables}

Social Background. As a measure of social background we use the highest educational level achieved by either the father or the mother. We distinguish between low educated (primary education, lower vocational track VBO or lower general track MAVO), medium educated (precollege track HAVO, preuniversity track VWO, or upper secondary vocational education $\mathrm{MBO}$ ), and high educated (vocational college $\mathrm{HBO}$ or university WO). ${ }^{9}$

The upper part of Table 4.1 shows that the share of low educated parents decreased over time, while the shares of medium and high educated parents clearly increased over time. Cross-tabulating parents' educational attainment with the child's first transition at age 12 shows that the relationship between social background and educational choices is rather stable over time (see Table A4.1 in the web appendix). In every cohort, some 60 percent of children from high educated households continue to precollege track (HAVO) or preuniversity track (VWO), while the corresponding figures for children from households with low educated parents are 1419 percent across the cohorts.

Academic Performance. As a measure of academic performance we use the average performance scores taken from arithmetic and language tests at age 12 . The tests in the four surveys are based on a nationwide 
compulsory test that is developed by CITO. These compulsory tests are usually conducted at the end of primary education and estimate the pupil's level of school-based knowledge, in line with national curriculum requirements. The test scores in the surveys are derived from a shortened version of the national CITO tests, ${ }^{10}$ which we have standardized to have a mean of 0 and a standard deviation of 1 . These scores are used as indicators of the performance level of the students at the beginning of secondary education. The test results in the data are comparable with those of the real CITO tests at the end of primary education (Hustinx et al. 2005). ${ }^{11}$

Measuring performance before the transition at age 17 or 18 to higher education is more challenging. It is not possible to use grades as measures of performance, because grades are specific to the different tracks in secondary education and therefore cannot be compared across tracks. Furthermore, test scores at age 17 or 18 are also unavailable, because the CITO test is administered only once in the survey, at age 12. Given these constraints, we are therefore forced to use the age 12 CITO test results in our analyses of the transition at age 17 or 18. It is possible to check the effect of using early test scores rather than scores measured close to the transition. For two cohorts (the 1977 and the 1981 cohorts), an additional test in mathematics and language was constructed by CITO and carried out in the third year of the cohort study, at around age 15. We will therefore repeat some analyses of primary and secondary effects using the test scores at age $15 .^{12}$

Table 4.2 displays the average performance scores of the pupils at age 12 across the four cohorts. Pupils with high educated parents perform best out of the three groups, with an average standardized score of 0.59 . Pupils with low educated parents have the lowest performance scores of the three groups. Over time, the average level of performance of children with low and medium educated parents slightly decreased, while the average

TA B LE $4 \cdot 2$

Means and standard deviations (in parentheses) of standardized performance scores at age 12, by birth cohort

\begin{tabular}{lcrrr}
\hline $\begin{array}{l}\text { Parents } \\
\text { education }\end{array}$ & 1965 & 1970 & \multicolumn{1}{c}{1977} & \multicolumn{1}{c}{1981} \\
\hline Low & $-0.22(0.971)$ & $-0.26(0.937)$ & $-0.31(0.965)$ & $-0.36(0.942)$ \\
Medium & $0.14(0.947)$ & $0.15(0.961)$ & $0.10(0.931)$ & $0.06(0.931)$ \\
High & $0.59(0.890)$ & $0.53(0.955)$ & $0.60(0.872)$ & $0.60(0.857)$ \\
\hline
\end{tabular}

S OURCE: CBS cohorts 1965, 1970,1977, and 1981 and our calculations. 
scores for children with high educated parents remained more or less stable. The average performance scores in the second test at age 15, for the 1977 and 1981 cohorts, do not differ much from those at age 12. Some deviations can be found for pupils with high educated parents; in the 1977 cohort, 15 -year-olds performed slightly better than at age 12 , while they did worse at 15 than at 12 in the 1981 cohort (see Table A4.2 in the web appendix).

\section{RESULTS}

We analyze the relative importance of primary and secondary effects on the basis of the method described in Chapter 2 of this book, which provides us with the opportunity to disentangle performance and choice in the context of social-background differences. We use this method for educational transitions at both age 12 and age 17 or 18 .

Before discussing the estimated relative importance of primary and secondary effects, we first discuss the factual and synthesized proportions of students making each transition.

\section{Transition at Age 12}

The diagonal numbers from the upper left corner to the lower right corner for each cohort in Table 4.3 show the actual probabilities of students from each social-background group making the transition to preuniversity track (VWO) and to precollege (HAVO) or preuniversity track (VWO). As a general observation we can note that the actual transition probabilities for all children have decreased by $3-4$ percentage points over time. In our reference cohort (1981), 6 percent of students with low educated parents, 14 percent of students with medium educated parents, and 40 percent of students with high educated parents proceeded to the preuniversity track (VWO). All other numbers in the table show synthesized proportions. To give an example, if in the 1981 cohort students from low educated parents had the average performance of students with high educated parents but had kept their own choice behavior constant, their probability of entering the preuniversity track would have increased from 6 percent to 21 percent. In contrast, if students from low educated parents had the choice behavior of the students with high educated parents but had kept their own performance constant, their probability of entering the preuniversity track would have increased from 6 percent to 14 percent. 


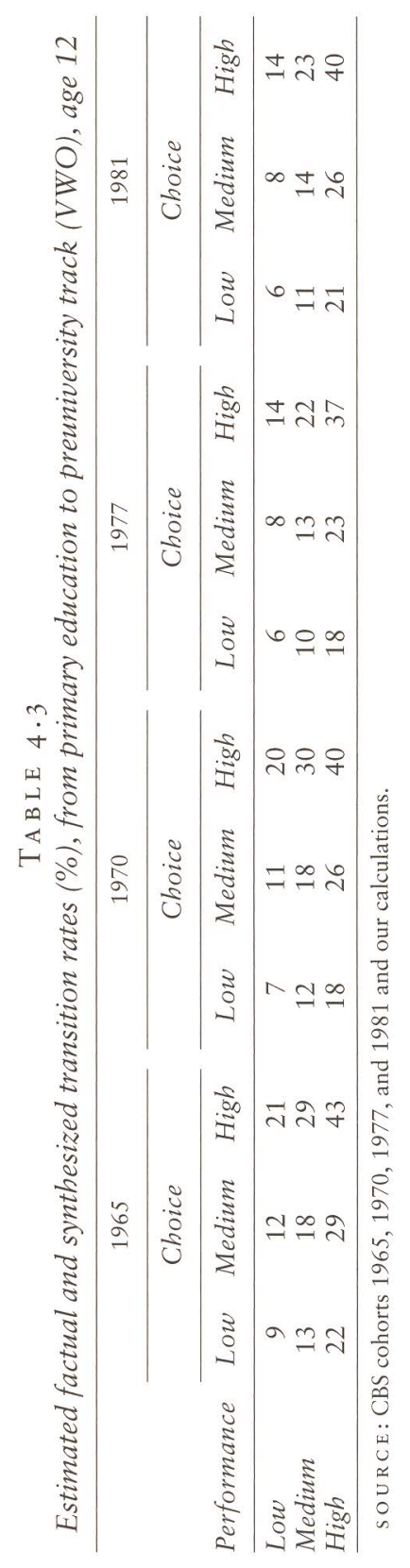


If we look at the synthesized proportions in Table 4.3, we can make two observations. First, for students from low educated backgrounds in the 1965 cohort, whether they adopted the performance level or adopted the choice behavior of students from high educated parents made little difference: both cases would lead to an increase in the probability of making the transition to the preuniversity track from the (actual) rate of 9 percent to a (synthesized) transition probability of 22 percent or 21 percent, respectively. In the 1981 cohort, however, these same transition propensities changed from 6 percent to 21 percent and 14 percent, respectively. That is, the performance-related differences between children from low and high educated parents increased over time, while the choice-related differences (with the exception of the 1970 cohort) remained more or less constant.

Table A4.3 in the web appendix shows results for a similar analysis of entry to precollege track (HAVO) or preuniversity track (VWO). Students with high educated parents have a high and relatively stable probability over time to proceed to one of these tracks (61 percent on average). In turn, the probability of going to precollege track or preuniversity track is for students with low educated parents on average 17 percent and for students with medium educated parents 32 percent, and for both groups slightly decreasing over time. In the 1981 cohort, 15 percent of the students with low, 30 percent with medium, and 64 percent with high educated parents proceeded to either precollege track or preuniversity track. Note that, regardless of changes over time, the probability of going to precollege track or preuniversity track, rather than to preuniversity track only, is about twice as high for students with low and medium educated parents and about 1.5 times higher for students with high educated parents. It suggests that the precollege track provides a crucial opportunity for students with low and medium educated parents to proceed to higher education. Again we can note that the performance-related differences between those with low and high educated parents have increased over time (especially between the first two and the last two cohorts), while the choice-related differences have stayed more or less the same.

\section{Primary and Secondary Effects at the Age-12 Transition}

Table 4.4 confirms these findings and shows that secondary effects on average declined in importance over time at the transition at age 12 (see also Figures A4.6 and A4.7 in the web appendix). Between the first two cohorts and the last two cohorts, the relative importance of secondary effects at 
TA B L E $4 \cdot 4$

Relative importance (\%) of secondary effects at age-12 transition from primary education to (1) preuniversity track (VWO) and (2) precollege track (HAVO) or preuniversity track (VWO)

\begin{tabular}{|c|c|c|c|c|c|c|c|c|}
\hline & \multicolumn{2}{|c|}{1965} & \multicolumn{2}{|c|}{1970} & \multicolumn{2}{|c|}{1977} & \multicolumn{2}{|c|}{1981} \\
\hline & (1) & (2) & (1) & (2) & (1) & (2) & (1) & (2) \\
\hline Medium-low & 45 & 40 & 46 & 47 & 34 & 36 & 30 & 34 \\
\hline High-low & 48 & 44 & 52 & 53 & 43 & 41 & 39 & 40 \\
\hline High-medium & 50 & 47 & 57 & 58 & 48 & 45 & 44 & 44 \\
\hline Average & 48 & 44 & 52 & 53 & 42 & 41 & 38 & 39 \\
\hline
\end{tabular}

S O U R E : CBS cohorts 1965, 1970, 1977, and 1981 and our calculations.

the transition to the preuniversity track (VWO) decreased from around 50 percent to around 40 percent. For the transition to either precollege track (HAVO) or preuniversity track (VWO), the percentages fluctuated a little more (with a clear outlier in the 1970 cohort), but we also note a (smaller) decrease from 44 percent in the 1965 cohort to 39 percent in the 1981 cohort. The relative importance of secondary effects over all cohorts is thus on average 45 percent at the transition to preuniversity track and 44 percent at the transition to precollege track or preuniversity track. Primary effects are on average slightly more important at this transition. Interestingly, the relative importance of secondary effects is highest when explaining the difference between students with medium and high educated parents.

The results we have obtained are, with small deviations, in line with those of Kloosterman et al. (2009) for the same cohorts. When we consider the 1965,1977 , and 1981 cohorts, the relative importance of primary effects increased between students from medium and low, high and low, and high and medium educated parents over time. The 1970 cohort interrupts this linear trend, and we observe a decrease in the relative importance of primary effects from 1965 to 1970 . Summarizing our findings, we can say that the primary effects outweigh the secondary effects at the transition at age 12 , but that nonetheless secondary effects are still substantial, even if their relative share appears to decrease over time.

\section{The Conditional Transition at Age 17 or 18}

Compared to the first transition at age 12, the actual transition rates at age 17 or 18 from preuniversity track (VWO) to university (WO) and from precollege (HAVO) or preuniversity (VWO) tracks to vocational college (HBO) or to university (WO) of students with low, medium, and high educated 
parents very clearly increased over time. The selection process at the first transition already functions as an important selection mechanism for the future transition into higher education. As Table 4.5 shows, students with low educated parents who graduated in the preuniversity track increased their probability of making the transition to university from 34 percent in the 1965 cohort to 42 percent in the 1981 cohort. Students with medium and high educated parents had generally higher, but-with the exception of the 1970 cohort - rather constant transition rates over time (with medium educated parents, 43 percent in the 1965 cohort and 46 percent in the 1981 cohort; with high educated parents, 54 percent in the 1965 cohort and 55 percent in the 1981 cohort). The increase in actual transition rates for those from low educated households is even clearer when looking at the transition to vocational college or to university (see Table A4.4 in the web appendix). The expansion of Dutch higher education, which mostly occurred because of an increase in enrollment in vocational colleges, facilitated access to higher education over time for students with low and medium educated parents.

The synthesized proportions in the off-diagonal numbers in Table 4.5 reveal that secondary effects are much stronger than primary effects at the transition at age 17 or 18 (see also Table A4.4 in the web appendix). Table 4.5, for example, shows for the 1981 cohort that if students with low educated parents keep their own performance distribution but have the transition propensity of students from high educated parents, their transition rate to university would be 54 percent (actual transition rate is 42 percent). The opposite is reported for students from high educated parents: if their average performance distribution is combined with the transition propensity of students with low educated parents, their transition rate to university would be 42 percent (actual transition rate is 55 percent). Differences in performance (vertical differences) are practically nonexistent at this transition. All differences between students from different educational backgrounds are therefore driven by secondary effects (horizontal differences). This is also true for the transition to vocational college or university (see Table A4.4 in the web appendix), supporting the argument that there are few differences in performance between students from different social backgrounds at this transition (no primary effects), but there are different preferences in choosing higher education (secondary effects). 


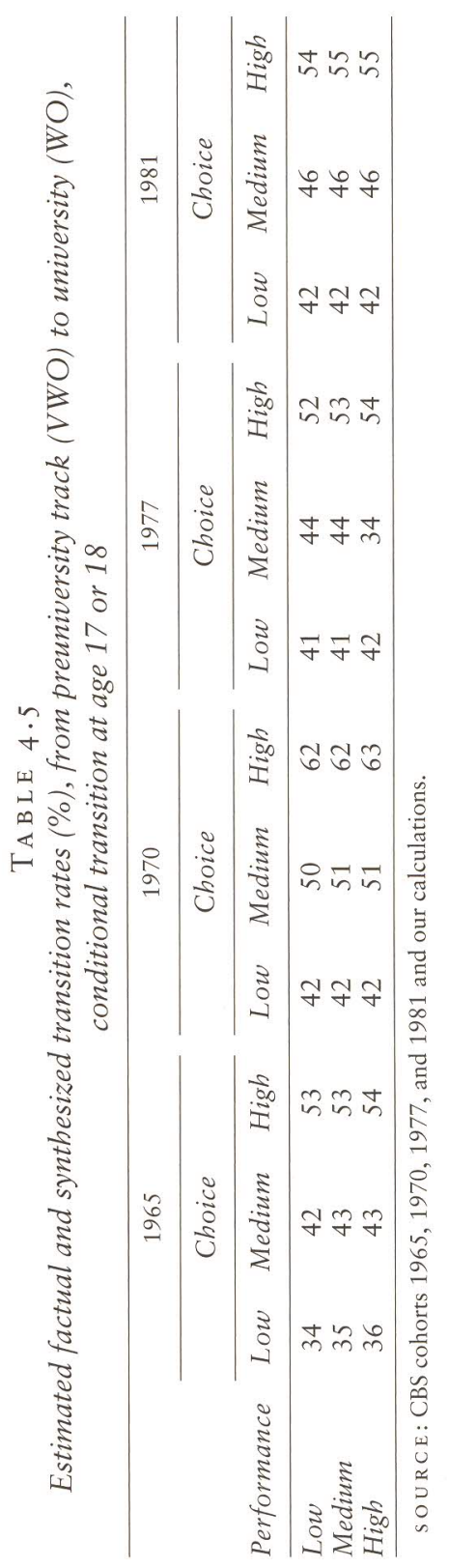


To sum up, primary effects at the transition at age 17 or 18 are quite small and change very little over time. The secondary effects are larger (although not as large as at the first transition at age 12) and explain most of the differences in observed social-background effects, although these effects clearly decrease over time.

\section{The Unconditional Transition at Age 17 or 18}

An unconditional analysis, that is, of all pupils to university (WO) and all pupils to vocational college (HBO) or university (WO), allows us to take into account the possibility of upward movements through alternative tracking paths in the Dutch educational system and thus provides a picture of overall IEO at this transition stage. As Table 4.1 illustrates, students are less likely to enter vocational college (HBO) or university (WO) in the unconditional model than in the conditional model, which suggests that students move on rather straight career paths. In the 1981 cohort, for instance, 50 percent of the students who graduated in the preuniversity track (VWO) made the transition to university, while only 8 percent did so when alternative tracking paths are considered. However, if we consider the transition to both vocational college and university, the share of students proceeding to higher-education tracks at the transition at age 17 or 18 clearly increases compared to the option to enroll only in university. A relatively constant share over time, of about 21 percent of the students coming from different school tracks, proceeds to either vocational college or university, while the average share proceeding to university is about 8 percent over time.

As would be expected, Table 4.6 shows that the factual and synthesized proportions in the unconditional model are much lower than in the conditional model (see Table A4.5 in the web appendix for equivalent proportions for the unconditional transition to vocational college or university). The factual transition probabilities to university and to vocational college or university for students with low, medium, and high educated parents are low and even decreasing over time. Over time, the unconditional average transition probability of students with the average performance and transition propensity of those with low educated parents is 3 percent to university and 10 percent to vocational college or university. Students with medium educated parents have an average transition probability of 7 percent to university and 21 percent to vocational college or university. The corresponding figures for students with high educated parents are on 


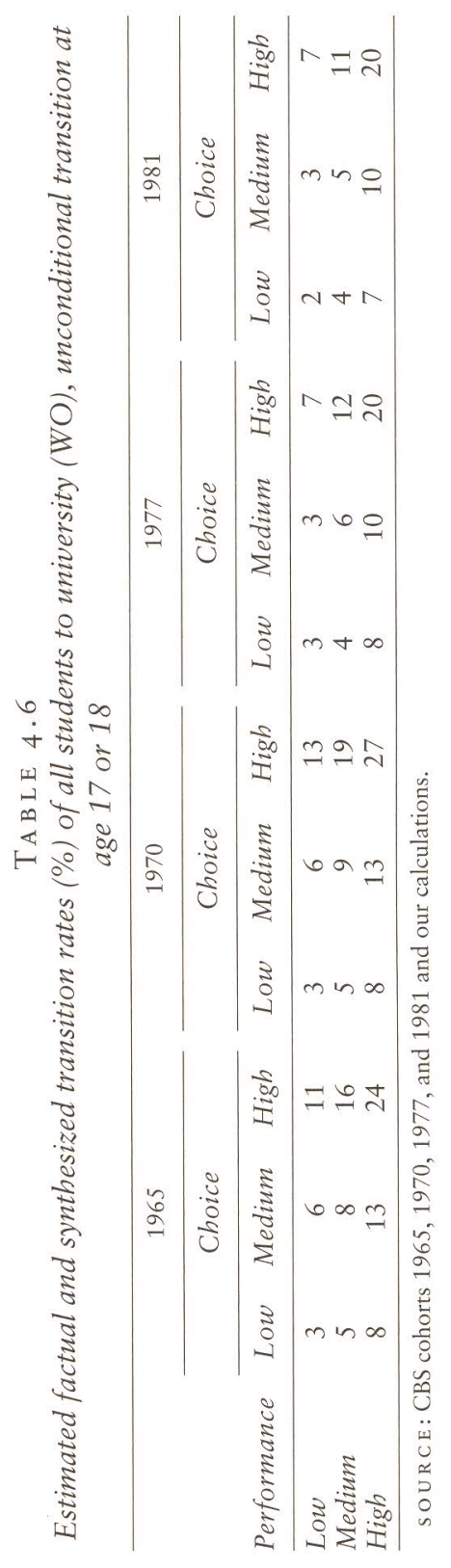


average 23 percent to university and 45 percent to vocational college or university. Again, including vocational college as a higher-education track clearly increases the probability of all groups participating in higher education. The percentage of students with low and medium educated parents going to vocational college or to university is three times as large as the percentage going exclusively to university. For students with high educated parents, this percentage is two times as large. The synthesized proportions suggest some higher influence of secondary effects in the first two cohorts, while the relationship between primary and secondary effects becomes more balanced in the two younger cohorts.

\section{Primary and Secondary Effects at the Age-17-18 Transition}

The relative importance of secondary effects in the conditional models in Table 4.7 somewhat fluctuates, indicating neither a clear decrease nor increase over time. The proportion of total inequality explained by secondary effects is generally high at an overall average level of 94 percent at the transition from preuniversity track (VWO) to university (WO) and at an overall average level of 81 percent at the transition from precollege track (HAVO) or preuniversity track (VWO) to vocational college (HBO) or university (WO) (see also Figures A4.8 and A4.9 in the web appendix). The relatively high importance of secondary effects at the transition from preuniversity track to university consolidates the transition to university as an elite path. The conditional transition to vocational college or university generates lower proportions of secondary effects than the transition to only university, but it does not offer too much in terms of a distinctive decrease

TAB LE $4 \cdot 7$

Relative importance (\%) of secondary effects at conditional transition at age 17 or 18: (1) from preuniversity track (VWO) to university (WO) and (2) from precollege track (HAVO) or preuniversity track (VWO) to vocational college ( $H B O)$ or university (WO)

\begin{tabular}{|c|c|c|c|c|c|c|c|c|}
\hline & \multicolumn{2}{|c|}{1965} & \multicolumn{2}{|c|}{1970} & \multicolumn{2}{|c|}{1977} & \multicolumn{2}{|c|}{1981} \\
\hline & (1) & (2) & (1) & (2) & (1) & (2) & (1) & (2) \\
\hline Medium-low & 90 & 79 & 93 & 87 & 91 & 71 & 94 & 84 \\
\hline High-low & 93 & 79 & 96 & 88 & 91 & 78 & 95 & 80 \\
\hline High-medium & 95 & 80 & 99 & 89 & 91 & 82 & 96 & 77 \\
\hline Average & 93 & 79 & 96 & 88 & 91 & 77 & 95 & 80 \\
\hline
\end{tabular}

S O U R E : CBS cohorts 1965, 1970, 1977, and 1981 and our calculations. 
TA B LE 4.8

Relative importance (\%) of secondary effects at unconditional transition at age 17 or 18: all students to (1) university (WO) and (2) vocational college (HBO) or university (WO)

\begin{tabular}{|c|c|c|c|c|c|c|c|c|}
\hline & \multicolumn{2}{|c|}{1965} & \multicolumn{2}{|c|}{1970} & \multicolumn{2}{|c|}{1977} & \multicolumn{2}{|c|}{1981} \\
\hline & (1) & (2) & (1) & (2) & (1) & (2) & (1) & (2) \\
\hline Medium-low & 56 & 54 & 54 & 57 & 39 & 42 & 39 & 49 \\
\hline High-low & 58 & 55 & 61 & 60 & 50 & 48 & 48 & 48 \\
\hline High-medium & 59 & 56 & 66 & 62 & 56 & 52 & 54 & 46 \\
\hline Average & 58 & 55 & 60 & 60 & 48 & 47 & 47 & 48 \\
\hline
\end{tabular}

S O U R C E: CBS cohorts 1965, 1970, 1977, and 1981 and our calculations.

in IEO over time. The findings at this transition suggest that, to a large extent, the dominance of secondary effects results from the selection process at the first transition. ${ }^{13}$

Looking at the unconditional models in Table 4.8, we note that the relative importance of secondary effects is clearly lower than in Table 4.7 and on average also decreases somewhat over time. It suggests that, insofar as any change occurred, this change appears at the transition at age 12 , rather than at the transition at age 17 or 18 . A comparison of these results with the relative importance of secondary effects at the first transition (Table A4.5 in the web appendix) suggests that at the transition at age 17 or 18 there are no possibilities to repair previous decisions: later choices do not compensate for the choices made at the first transition. The proportions of secondary effects both at the transition to university and at the transition to vocational college or university are even higher than at the first transition at age 12, suggesting an ongoing selection in favor of pupils with high educated parents. Over time, the relationship between students with high and low, and high and medium educated parents shows that those of lower social background did catch up to some extent with those of higher social backgrounds but that secondary effects appear to remain more important than primary effects at these later transitions. The unconditional models suggest an average overall relative importance of secondary effects of 53 percent.

\section{CONCLUSION}

This chapter has assessed the relative importance of primary and secondary effects at the transitions at age 12 (entry to secondary education) and age 17 
or 18 (entry to higher education) in the Dutch educational system over time. Using panel data from four birth cohorts, we made an explicit distinction between the most prestigious and less prestigious routes in the higher tracks of secondary and higher education. In particular, we differentiate between the preuniversity track (VWO) and the precollege track (HAVO) in secondary education and between university (WO) and vocational college ( $\mathrm{HBO}$ ) in higher education. Usually regarded as the less prestigious track in higher education, vocational college has gained in popularity among students over time. In particular, students from low and medium educated parents who complete a precollege track or a preuniversity track are choosing to enter higher education through vocational college. Students from high educated parents, in contrast, are more likely to choose straight career paths from preuniversity track to university.

Our results show that the relative importance of secondary effects at the first transition at age 12 has decreased over time and now amounts to an average of 38 percent of total IEO at this transition. While secondary effects lose some of their power at this transition, their importance clearly grows at later educational transitions. At the conditional transition to higher education at age 17 or 18, secondary effects gain a great deal in importance and almost exclusively explain the (conditional) transition to university (WO). While the proportions in the conditional model stay rather stable over time, the unconditional model at this transition shows a modest decrease in the relative importance of secondary effects, due to changes in the importance of secondary effects at the first transition. Although the Dutch educational system claims to be meritocratic in its selection into the different tracks of secondary education, we can observe that a large proportion of IEO is still related to differential preferences across social-background groups. At this point, almost 40 percent of the IEO differences are choice related.

The situation does not improve if we look at later transitions. At age 17 or 18 secondary effects have increased rather than decreased over the career, despite the Dutch educational system offering opportunities to repair mistakes by allowing moves between tracks. The decrease in secondary effects over time (from some 60 percent to some 48 percent) is mainly due to changes at the first transition at age 12 .

These findings imply that policy measures by the Dutch government to reduce IEO have mainly been successful at the first transition to secondary education but have largely failed at later transition stages. To provide 
an example, a 1993 reform aimed to restructure secondary education. The so-called Basisvorming was supposed to provide pupils of all secondary education tracks with a standardized basic curriculum in the first three years of secondary education and an opportunity to prove their abilities and preferences over a longer period before deciding on a final track. However, as shown in the evaluation by the Dijsselbloem parliamentary committee (see Borghans et al. 2008), this reform did not lead to a considerable reduction in IEO. Pupils in our most recent birth cohort (the 1981 cohort) should have profited from this restructuring and subsequently experienced reduced inequality after entering secondary education. And yet the difference in IEO between this cohort and the previous cohort in our analysis is hardly detectable.

NOTES

1. Although Kloosterman (2010) includes an analysis of the transition to postsecondary education in her doctoral dissertation, she focuses on upward and downward movements within tertiary education.

2. CITO stands for Centraal Instituut voor Toets Ontwikkeling, which is the Dutch central institute for test development that provides the tests to primary schools nationwide.

3. At age 17 students are still obliged to follow formal education for at least two days per week.

4. These cases are included in the lower vocational track (VBO) in our analysis.

5. Teachers often give mixed recommendations for secondary school tracks if, for instance, the CITO test results are not clear-cut or they diverge from the overall impression that a teacher has of a pupil.

6. A student is understood to have successfully completed an educational track if he or she passed the final examination. If a student dropped out before finishing a grade, we consider the most recent available information about his or her educational transitions.

7. Corresponding figures for the other cohorts are available in Figures A4.3A4.5 of the web appendix (http://www.primaryandsecondaryeffects.com). See also Table 4.1 for changes over time.

8. Each of the transition variables is binary, taking a value of 1 when making the transition and 0 otherwise. In the case of mixed tracks in the orientation years of secondary education, we look at the first clear track decision after the orientation phase (cf. Kloosterman et al. 2009, 383).

9. In the CBS survey of the 1970 cohort, information on parents' education was collected differently from the surveys of the other three cohorts. This may cause some distinct deviations from a trend when we compare results over time. 
10. Pupils in the survey thus complete these tests twice; once, officially, at the end of primary education and once as a respondent in the survey. Choices for subsequent school tracks have already been made on the basis of the regular CITO test. In contrast to the 1965, 1977, and 1981 cohorts, the 1970 cohort took the survey-specific CITO test at the same time as the real CITO test, i.e., one year earlier. This leads to comparably lower performance scores in the survey for pupils of the 1970 cohort (CBS 1992).

11. According to Hustinx et al. (2005), the Cronbach's alpha of the CITO tests in the 1965 and 1970 birth cohorts is 0.80 .

12. The use of the second test is unfortunately still problematic, due to three factors. First, as a result of the design of the data collection, pupils who had to repeat classes at any stage before the second test did not participate in this test. Second, the tests were not the same for each pupil. There was a relatively simple test for those who at age 15 were in the lower general track (MAVO) or the lower vocational track (VBO) and another, more difficult, test for pupils in the precollege track (HAVO) and the preuniversity track (VWO). Although some recalibration has taken place, the resulting test scores do not provide a perfect estimate of performance at age 15. Third, since the higher-education track is chosen at age 17 or 18 , the second test at age 15 cannot provide a perfect proxy for pupils' performance at this later transition. Given these restrictions, the second test will not guarantee a completely unbiased comparison between performance and choice at the transition to higher education across different social backgrounds.

13. We performed an additional test using performance test scores at age 15 (see Table A4.6 in the web appendix). There are some differences between the results using performance tests at age 15 and those using performance tests at age 12. Table A4.6 shows that when employing performance scores at age 15 the average relative importance of secondary effects at the transition to vocational college ( $\mathrm{HBO}$ ) or university (WO) is lower in the 1977 cohort (38 percent) and almost the same in the 1981 cohort (47 percent), compared to the analyses employing performance scores at age 12 . In comparing particular background groups, we see that, when employing performance scores at age 15 , for both cohorts the relative importance of secondary effects is lowest between pupils of medium and low educated background, moderate between pupils of high and low educated background, and highest between pupils of high and medium educated background. While this trend is also found using test scores at age 12 in the 1977 cohort, it differs for the 1981 cohort.

\section{REFERENCES}

Bakker, Bart F. M., and Peter G. J. Cremers. 1994. "Gelijke kansen in het onderwijs? Een vergelijking van vier cohorten leerlingen in hun overgang naar het voortgezet onderwijs." Tijdschrift voor Onderwijsresearch 19:191-203. 
Bakker, Bart F. M., Jaap Dronkers, and Huibert Schijf. 1982. "Veranderingen in individuele schoolloopbanen tussen 1959 en 1977 in de stad Groningen." Mens en Maatschapij 57:253-66.

Bakker, Bart F. M., and Siebe P. Schouten. 1991. "Trends in onderwijskansen: Een vergelijking van de overgang naar het voortgezet onderwijs van de generaties geboren rond 1953, 1965, en 1971.” Sociale Wetenschappen 34:1-22. Blossfeld, Hans-Peter, and Yossi Shavit. 1993. "Persisting Barriers: Changes in Educational Opportunities in Thirteen Countries." In Persistent Inequality: Changing Educational Attainment in Thirteen Countries, edited by Yossi Shavit and Hans-Peter Blossfeld, 1-24. Boulder, CO: Westview.

Borghans, Lex, Rolf van der Velden, Charlotte Büchner, Johan Coenen, and Christoph Meng. 2008. "Het meten van onderwijskwaliteit en de effecten van recente onderwijsverniewingen." In Commissie Parlementair Onderzoek Onderwijsvernienwingen. Tijd voor Onderwijs, Deelrapport lV, 3-114. The Hague: SDU uitgevers.

Bosma, Hans, and Peter G. J. Cremers. 1996. "Sociaal-economische Verschillen bij de Doorstroom naar de Universiteit." Mens en Maatschapij 71:142-253.

Buis, Maarten L. 2010. "Inequality of Educational Outcome and Inequality of Educational Opportunity in the Netherlands during the 20th Century." PhD diss. Amsterdam: Free University.

CBS (Centraal Bureau voor de Statistiek). 1992. "Schoolloopbaan en herkomst van leerlingen bij het voortgezet onderwijs; vergelijking tussen de cohorten 1977 en 1982." Unpublished manuscript.

CITO. 2010. Terugblik en resultaten 2010. Eindtoets Basisonderwijs, Groep 8, versie April 20, 2010. Arnhem: Centraal Instituut voor Toetsontwikkeling.

De Graaf, Paul M., and Harry B. G. Ganzeboom. 1993. "Family Background and Educational Attainment in the Netherlands for the 1891-1960 Birth Cohorts." In Persistent Inequality: Changing Educational Attainment in Thirteen Countries, edited by Yossi Shavit and Hans-Peter Blossfeld, 75-100. Boulder, CO: Westview.

De Graaf, Paul M., and Maarten H. J. Wolbers. 2003. "The Effects of Social Background, Sex, and Ability on the Transition to Tertiary Education in the Netherlands." The Netherlands Journal of Social Sciences 39:172-201.

De Jong, Uulkje, Jaap Dronkers, and Willem E. Saris. 1982. "Veranderingen in de Schoolloopbanen tussen 1965 en 1977: Ontwikkelingen in de Nederlandse Samenleving en in haar Onderwijs." Mens en Maatschapij 57:26-54.

Dronkers, Jaap. 1983. "Have Inequalities in Educational Opportunities Changed in the Netherlands? A Review of Empirical Evidence." The Netherlands Journal of Sociology 19:133-50. - 1993. "Educational Reform in the Netherlands-Did It Change the Impact of Parental Occupation and Education?" Sociology of Education $66: 262-77$. 
Erikson, Robert, John H. Goldthorpe, Michelle Jackson, Meir Yaish, and David R. Cox. 2005. "On Class Differentials in Educational Attainment." Proceedings of the National Academy of Sciences 102:9730-33.

Hustinx, Paul W. J., Hans Kuyper, Margaretha P. C. van der Werf, and Djurre Zijsling. 2005. Beschrijving Leerlingsbestanden VOCL '89. Groningen, Netherlands: Gronings Instituut voor onderzoek van onderwijs, opvoeding en ontwikkeling.

Jackson, Michelle, Robert Erikson, John H. Goldthorpe, and Meir Yaish. 2007. "Primary and Secondary Effects in Class Differentials in Educational Attainment: the Transition to A-Level Courses in England and Wales." Acta Sociologica 50:211-29.

Kloosterman, Rianne. 2010. "Social Background and Children's Educational Careers. Studies into the Primary and Secondary Effects of Social Background over Transitions and over Time in the Netherlands.” PhD diss. Nijmegen, Netherlands: Radboud University Nijmegen.

Kloosterman, Rianne, Stijn Ruiter, Paul M. de Graaf, and Gerbert Kraaykamp. 2009. "Parental Education, Children's Performance and the Transition to Higher Secondary Education: Trends in Primary and Secondary Effects over Five Dutch School Cohorts (1965-1999)." British Journal of Sociology 60:377-98.

Kraaykamp, Gerbert, Koen Van Eijck, and Wout Ultee. 2010. "Status, Class and Culture in the Netherlands." In Social Status and Cultural Consumption, edited by Tak Wing Chan, 159-88. Cambridge: Cambridge University Press.

Peschar, Jules L., Els Ten Vergert, and Roel Popping. 1986. "From Father to Son and from Father to Daughter: Educational Mobility in Hungary and the Netherlands for the Birth Cohorts from 1925 to 1955." Quality and Quantity 20:377-403.

Rijken, Susanne, Ineke Maas, and Harry B. G. Ganzeboom. 2007. “The Netherlands: Access to Higher Education-Institutional Arrangements and Inequality of Opportunity." In Stratification in Higher Education. A Comparative Study, edited by Yossi Shavit, Richard Arum, and Adam Gamoran, 266-93. Stanford, CA: Stanford University Press.

Sieben, Inge, Johannes Huinink, and Paul M. De Graaf. 2001. "Family Background and Sibling Resemblance in Educational Attainment: Trends in the Former FRG, the Former GDR and the Netherlands." European Sociological Review 17:401-30.

Tieben, Nicole, Nan Dirk De Graaf, and Paul M. De Graaf. 2010. "Changing Effects of Family Background on Transitions to Secondary Education in the Netherlands. Consequences of Educational Expansion and Reform." Research in Social Stratification and Mobility 28:77-90.

Tieben, Nicole, and Maarten H.J. Wolbers. 2010. "Transitions to Post-Secondary Education in the Netherlands: A Trend Analysis of Unconditional and Conditional Socio-Economic Background Effects." Higher Education 60:85-100. 
Traag, Tanja, and Rolf K. W. Van der Velden. 2011. "Early School-Leaving in the Netherlands. The Role of Family Resources, School Composition and Background Characteristics in Early School-leaving in Lower Secondary Education." Irish Educational Studies 30:45-62.

Van Heek, Frederik. 1968. Het Verborgen Talent. Milieu, Schoolkenze en Schoolgeschicktheid. Meppel, Netherlands: J. A. Boom.

Vrooman, Cok, and Jaap Dronkers. 1986. "Changing Educational Attainment Processes: Some Evidence from the Netherlands." Sociology of Education 59:69-78.

Willemse, Paula. 1987. "Overleving in de Bovenstroom van het Voortgezet Onderwijs: Veranderde Milieu-Effekten voor Jongens en Meisjes.” Tijdschrift voor Onderwijsresearch 12:329-43. 